\title{
Physiochemical properties of highly cross-linked maize starches and their enzymatic digestibilities by three analytical methods
}

\begin{abstract}
Waxy maize, normal maize and high amylose maize starches were highly cross-linked (CL) with phosphate groups. The CL starches were characterized by phosphorus content, settling volume, gelatinization temperature, pasting curve, X-ray diffraction and microscopy. Their digestibilities were determined by the Englyst, Available Carbohydrate Dietary Fiber (ACDF), and AOAC 991.43 methods where starch digestion with $\alpha$-amylase was done, respectively, at 37,80 and $95{ }^{\circ} \mathrm{C}$. The CL waxy maize starch had $\sim 10 \%$ more phosphorus content $(0.36 \%$ vs $0.32 \%$ ) than the CL normal and high-amylose maize starches. Total dietary fiber (TDF) levels of the unmodified and CL starches determined by the AOAC and ACDF methods increased with increasing amylose content. The resistant starch (RS) contents of the three CL starches decreased in the order, CL high amylose (85\%) > CL waxy (82\%) > CL normal (61\%) maize starch. The digestibilities of the unmodified and CL maize starches at 80 and $95{ }^{\circ} \mathrm{C}$ were positively correlated with their settling volumes at those temperatures, indicating that increased granule swelling decreased TDF levels. Photomicrographs of the starch granules after digestion in the TDF and RS assays showed less internal erosion of granules in CL high-amylose starch compared to CL normal and waxy maize starches.
\end{abstract}

Keyword: Cross-linked maize starch; Amylose content; Digestibility; Granule swelling 